\title{
ANALISIS KERENTANAN DAERAH RAWAN BANJIR BERBASIS SISTEM INFORMASI GEOGRAFIS (Studi Kasus : Kecamatan Sekarbela - Kota Mataram)
}

\author{
Andi Syamsul Fajri ${ }^{1}$, Baiq Harly Widayanti ${ }^{2}$ \\ ${ }^{1,2}$ Program Studi Teknik Perencanaan Wilayah dan Kota Fakultas Teknik Universitas Muhammadiyah Mataram
} mapfazri@gmail.com

\section{INFO ARTIKEL}

Riwayat Artikel:

Diterima: 04-11-2017

Disetujui: 16-01-2018

\section{Kata Kunci:}

Banjir

AHP Pairwise

Comparison

Overlay Intresection.

\section{A. LATAR BELAKANG}

Pada dasarnya Indonesia adalah negara yang memiliki 2 (dua) musim yakni musim hujan dan musim kemarau. Musim kemarau sendiri biasanya terjadi

\begin{abstract}
Abstrak: Pada dasarnya Indonesia adalah negara yang memiliki 2 musim yakni musim hujan dan musim kemarau. Musim kemarau yang terjadi antara bulan Maret hingga Bulan Agustus sedangkan musim hujan yang terjadi September sampai bulan Februari. Akibatnya dengan jumlah bulan hujan yang relatif lebih banyak dari musim kemarau menjadikan beberapa wilayah di Indonesia banyak mengalami bencana banjir. Berdasarkan data BPBD Kota Mataram tahun 2011-2015 Kota Mataram memiliki daerah langganan banjir tiap tahunnya yaitu salah satunya Kecamatan Sekarbela. Dengan kondisi fisik wilayah perkotaan yang datar serta kondisi drainase yang saat ini tidak berfungsi optimal. sejumlah ruas jalan dan kawasan perumahan yang ada di Kecamatan Sekarbela tergenang dan terjadi banjir. Sebagai salah satu upaya dalam mengatasi banjir yaitu memetakan kerentanan daerah rawan banjir melalui pemetaan kawasan yang terindikasi rawan bencana banjir melalui Pemetaan Digital Berbasis Sistem Informasi Geografis. pemetaan daerah rawan banjir merupakan salah satu cara pengendalian secara non-struktural. Analisis Daerah Rawan Banjir pada penelitian ini menggunakan 3 varaibel penelitian yakni Kemiringan Lereng, Penggunaan Lahan, dan Infiltrasi Tanah dengan menggunakan 2 metode analisis yakni Analytic Hierarchy Process (AHP) Pairwise Comparison dan Overlay Intersection. Hasil analisa semua parameter dibandingkan dan diberi bobot menggunakan metode AHP matriks Pairwise Comparison. Diperoleh nilai bobot untuk Kemiringan Lereng adalah 0,89, Penggunaan Lahan 0,22 dan Infiltrasi Tanah 0,10. Seluruh hasil analisa digabung menggunakan metode Overlay Intersection pada ArcGIS10.3 untuk menghasilkan peta daerah rawan banjir. Diperoleh 95,11 \% daerah di Kecamatan Sekarbela adalah Rentan Banjir, 4,89 daerah paling Sangat Rentan.
\end{abstract}

\begin{abstract}
Basically Indonesia is a country that has 2 seasons namely the rainy season and the dry season. The dry season occurs between March and August while the rainy season is September to February. As a result with the number of months of rain that is relatively more than the dry season makes some areas in Indonesia suffered many floods. Based on data from BPBD Kota Mataram in 2011-2015 Mataram city has subscription area of flood every year that is one of Sekarbela Subdistrict. With the physical condition of flat urban areas and drainage conditions that are currently not functioning optimally. a number of roads and residential areas in the District Sekarbela flooded and flooding occurred. As one of effort to overcome flood that is mapping vulnerability of flood prone area through mapping of area that indicated flood disaster through Digital Mapping Based on Geographic Information System. mapping of flood prone areas is one of the ways of non-structural control. Analysis of Flood Prone Areas in this study used 3 research variables ie Slope Slope, Land Use, and Soil Infiltration using 2 analytical methods ie Analyze Hierarchy Process (AHP) Pairwise Comparison and Overlay Intersection. The results of the analysis of all parameters were compared and weighted using the Pairwise Comparison AHP matrix method. Obtained weight value for Slope Tilt is 0.89, Land Use 0.22 and Soil Infiltration 0.10. All analysis results are combined using Overlay Intersection method in ArcGIS10.3 to generate map of flood prone area. Obtained $95.11 \%$ of the area in Sekarbela Subdistrict is Vulnerable Flood, 4.89 Most Vulnerable Areas.
\end{abstract}

antara bulan Maret hingga Bulan Agustus sedangkan musim hujan sendiri terjadi September sampai bulan Februari. Akibatnya dengan jumlah bulan hujan yang relatif lebih banyak dari musim kemarau menjadikan 
dibeberapa wilayah di Indonesia banyak terjadi bencana banjir. Selain debit air hujan yang tingginya $>70 \mathrm{~cm}$ ada beberapa alasan mendasar yang menyebabkan wilayah daerah rawan banjir terjadi bencana banjir yakni, faktor non fisik seperti rusaknya sarana dan prasarana perkotaan menyebabkan terjadi bencana banjir.

Begitu juga Kota Mataram sendiri. berdasarkan data BPBD Kota Mataram tahun 2011-2015 Kota Mataram memiliki daerah langganan banjir tiap tahunnya yaitu salah satunya Kecamatan Sekarbela. Menurut BPBD Kota Mataram dari tahun 2011-2015 Kecamatan Sekarbela dihadapkan dengan masalah banjir setiap tahunnya yang mengakibatkan kerugian materil. Dengan kondisi fisik wilayah perkotaan yang datar serta kondisi drainase yang saat ini tidak berfungsi optimal, setiap kali terjadi hujan yang mengguyur Kecamatan Sekarbela lebih dari 3 jam, sejumlah ruas jalan dan kawasan perumahan yang ada di Kecamatan Sekarbela tergenang dan terjadi banjir.

Untuk mengatasi masalah tersebut, selain melakukan kegiatan mitigasi bencana khususnya bencana banjir, diperlukan juga upaya untuk memetakan Kerentanan Rawan Daerah Bencana Banjir. Salah satu upaya memetakan kerentanan daerah rawan banjir melalui pemetaan kawasan yang terindikasi rawan bencana banjir melalui Pemetaan Digital Berbasis Sistem Informasi Geografis.

Dengan menggunakan Sistem Informasi Geografi ini, kelengkapan bentuk permukaan bumi akan diintrerpretasikan kedalam bentuk gambar yang sangat sederhana dan mudah untuk digunakan, dalam pengolahannya. Untuk memperjelas bagaimana penanganan bencana banjir yang ada di Kecamatan Sekarbela tersebut, maka akan diangkat tema dengan judul "Analisis Klasifikasi Tingkat Kerentanan Daerah Rawan Banjir Berbasis Sistem Informasi Geografis”.

\section{TUJUAN PENELITIAN}

Tujuan dari penelitian adalah sebagai berikut :

$>$ Untuk mengetahui Klasifikasi Tingkat Kerentanan Daerah Banjir dan pemetaan lokasi kawasan Daerah Rawan Banjir di Kecamatan Sekarbela dengan menggunakan Aplikasi Sistem Informasi Geografis (SIG); dan

$>$ Untuk mengetahui arahan penanganan pada daerah rentan banjir di Kecamatan Sekarbela.

\section{RUANG LINGKUP PENELITIAN}

Kecamatan Sekarbela adalah sebuah Kecamatan yang terletak di sisi paling barat dari Provinsai Nusa Tenggara Barat (NTB) seklaigus Kota Mataram serta menjadi daerah langganan banjir setiap tahun (BPBD Kota Mataram). Kecamatan Sekarbela berda pada $08^{\circ} 33^{\prime}$ dan $08^{\circ} 38^{\prime}$ Lintang Selatan dan antara $116^{\circ} 04^{\prime}-116^{\circ} 10^{\prime}$ Bujur Timur., serta berada di pulau Lombok dan berbatasan langsung dengan :
Sebelah Barat

Sebelah Timur

Sebelah Utara

: Selat Lombok

Sebelah Selatan : Kecamatan Labu Api

Kecamatan Sekarbela memiliki luas $10.31 \mathrm{~km}^{2}$ dengan memiliki 5 (lima) kelurahan yakni Kelurahan Kekalik Jaya, Kelurahan Tanjung Karang, Kelurahan Tanjung Karang Permai, Kelurahan Karang Pule, serta Kelurahan Jempong.

\section{B. METODE PENELITIAN}

1. VARIABEL PENELITIAN

Menurut Nurhadi, Diah Respati Suryo S, dan Nurul Khotimah menyatakan bahwa Variabel Penelitian kali ini memiliki 3 (tiga) yakni Kemiringan Lereng, Penggunaan Lahan, dan Infiltrasi Tanah. Mak standar dari masingmasing variabel penelitian adalah :

Tabel 1.STANDAR KERENTANAN DARI KEMIRINGAN LERENG

\begin{tabular}{|c|c|c|c|c|c|}
\hline $\begin{array}{c}\text { KRITE } \\
\text { RIA }\end{array}$ & $\begin{array}{l}\mathrm{KE} \\
\mathrm{LAS}\end{array}$ & $\begin{array}{l}\text { KERENTAN } \\
\text { AN }\end{array}$ & $\begin{array}{l}\text { HAR } \\
\text { KAT }\end{array}$ & $\begin{array}{c}\text { BO } \\
\text { BOT }\end{array}$ & $\begin{array}{l}\text { SK } \\
\text { OR }\end{array}$ \\
\hline Datar & $0-2 \%$ & $\begin{array}{l}\text { Sangat } \\
\text { Rawan }\end{array}$ & 5 & \multirow[t]{5}{*}{5} & 25 \\
\hline Landai & $3-7 \%$ & Rawan & 4 & & 20 \\
\hline $\begin{array}{c}\text { Agak } \\
\text { Curam }\end{array}$ & $\begin{array}{c}8- \\
15 \%\end{array}$ & $\begin{array}{l}\text { Cukup } \\
\text { Rawan }\end{array}$ & 3 & & 15 \\
\hline Curam & $\begin{array}{l}15^{-} \\
21 \%\end{array}$ & Aman & 2 & & 10 \\
\hline $\begin{array}{l}\text { Sangat } \\
\text { Curam }\end{array}$ & $>21 \%$ & $\begin{array}{l}\text { Sangat } \\
\text { Aman }\end{array}$ & 1 & & 5 \\
\hline
\end{tabular}

Sumber : Zuidan (1979), SR FAO dan Staff (1983) dan Eko Kustiyanto (2004:38) dengan modifikasi

\section{Tabel 2.STANDAR KERENTANAN DARI PENGGUNAAN LAHAN}

\begin{tabular}{|c|c|c|c|}
\hline \hline PENGGUNAAN LAHAN & HARKAT & BOBOT & SKOR \\
\hline \hline $\begin{array}{c}\text { Lahan Terbuka, Sungai ,dan } \\
\text { Rawa }\end{array}$ & 5 & & 15 \\
\hline Landai & 4 & \multirow{3}{*}{3} & 12 \\
\hline Agak Curam & 3 & & 9 \\
\hline Curam & 2 & & 6 \\
\hline Sangat Curam & 1 & & 3 \\
\hline
\end{tabular}

Sumber : Gunawan (1991), Suprogo (1993) dan Eko Kustiyanto (2004:37) dengan modifikasi

Tabel 3.STANDAR KERENTANAN DARI INFILTRASI TANAH

\begin{tabular}{|c|c|c|c|c|c|}
\hline \hline $\begin{array}{c}\text { KRITE } \\
\text { RIA }\end{array}$ & $\begin{array}{c}\text { TEKSTU } \\
\text { R } \\
\text { TANAH }\end{array}$ & $\begin{array}{c}\text { INFILTR } \\
\text { ASI }\end{array}$ & $\begin{array}{c}\text { HARK } \\
\text { AT }\end{array}$ & $\begin{array}{c}\text { BOB } \\
\text { OT }\end{array}$ & SKOR \\
\hline \hline Halus & $\begin{array}{l}\text { Liat, liat } \\
\text { berdebu, } \\
\text { liat } \\
\text { berpasir }\end{array}$ & $\begin{array}{c}\text { Sangat } \\
\text { Jelek }\end{array}$ & 5 & & 25 \\
\hline Agak & $\begin{array}{l}\text { Lempun } \\
\text { g berliat, }\end{array}$ & $\begin{array}{l}\text { Jelek } \\
\text { lempung } \\
\text { liat } \\
\text { berdebu, } \\
\text { lempung } \\
\text { liat } \\
\text { berpasir }\end{array}$ & 4 & 2 & 20 \\
\cline { 2 - 3 } Sedang & Lempun & Sedang & 3 & & \\
\cline { 2 - 3 } & & & & 15 \\
\hline
\end{tabular}




\begin{tabular}{|c|c|c|c|c|}
\hline & $\begin{array}{l}\text { g, } \\
\text { lempung } \\
\text { berdebu, } \\
\text { debu, } \\
\text { lempung } \\
\text { berpasir } \\
\text { sangat } \\
\text { halus }\end{array}$ & & & \\
\hline $\begin{array}{c}\text { Agak } \\
\text { Kasar }\end{array}$ & $\begin{array}{l}\text { Lempun } \\
\mathrm{g} \\
\text { berpasir } \\
\text { halus, } \\
\text { lempung } \\
\text { berpasir }\end{array}$ & Baik & 2 & 10 \\
\hline Kasar & $\begin{array}{l}\text { Lempun } \\
\text { g } \\
\text { berpasir } \\
\text { halus, } \\
\text { lempung } \\
\text { berpasir }\end{array}$ & $\begin{array}{c}\text { Sangat } \\
\text { Baik }\end{array}$ & 1 & 5 \\
\hline
\end{tabular}

Sumber : Sinatala Arsyad (1989) dalam Abdi Tunggal P, (2002:55) dengan modifikasi

\section{PENENTUAN TINGKAT KEPENTINGAN}

Pada analisis yang digunakan untuk mengklasifikasikan daerah rentan banjir adalah Analisis Hirarki Proses Pairwise Comparison dan Overlay Intersection. Kedua hasil analisis ini kemudian dikombinasikan untuk mendapatkan Peta Tingkat Klasifikasi Daerah Rentan Banjir di Kecamatan Sekarbela. Tapi sebelum itu harus dilakukan penentuan tingkat kepentingan beberapa variabel penelitian untuk menentukan variabel apa saja yang paling berpengaruh terjadinya bencana banjir. Untuk akan ditampilkan pada tabel 4 dibawah ini :

Tabel 4. PENENTUAN TINGKAT KEPENTINGAN

\begin{tabular}{|c|c|c|}
\hline $\begin{array}{l}\text { PARAMETER } \\
\end{array}$ & $\begin{array}{l}\text { PENENTUAN TINGKAT } \\
\text { KEPENTINGAN }\end{array}$ & $\begin{array}{c}\text { TING. } \\
\text { KEPENTINGAN }\end{array}$ \\
\hline $\begin{array}{l}\text { Kemringan } \\
\text { Lereng }\end{array}$ & 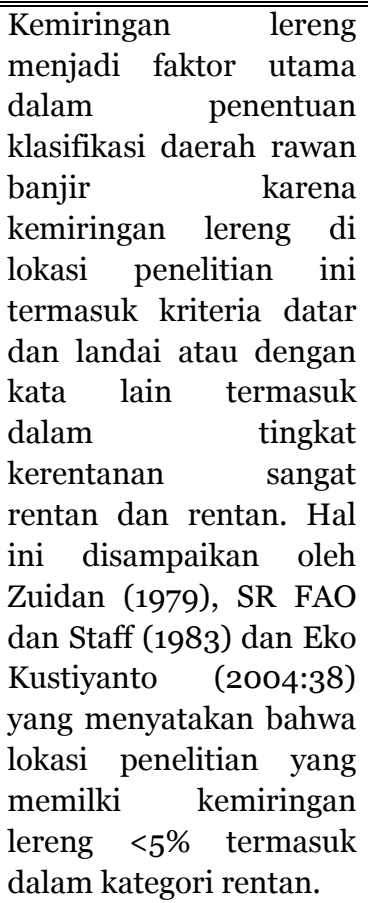 & 1 \\
\hline $\begin{array}{l}\text { Penggunaan } \\
\text { Lahan }\end{array}$ & 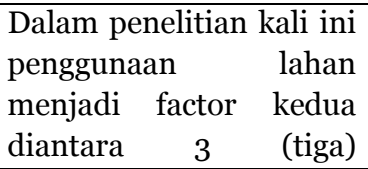 & 2 \\
\hline
\end{tabular}

\begin{tabular}{|c|c|c|}
\hline & 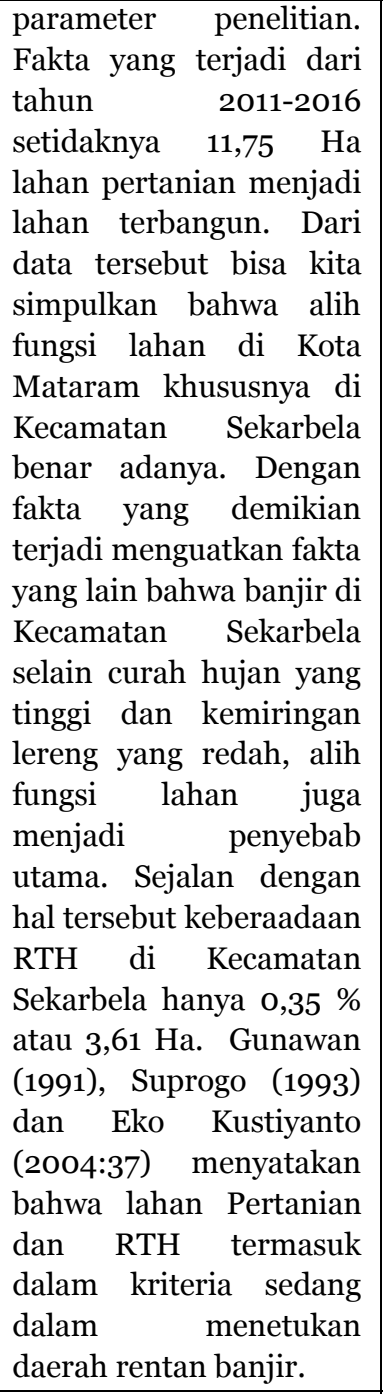 & \\
\hline $\begin{array}{l}\text { Infiltrasi } \\
\text { Tanah }\end{array}$ & 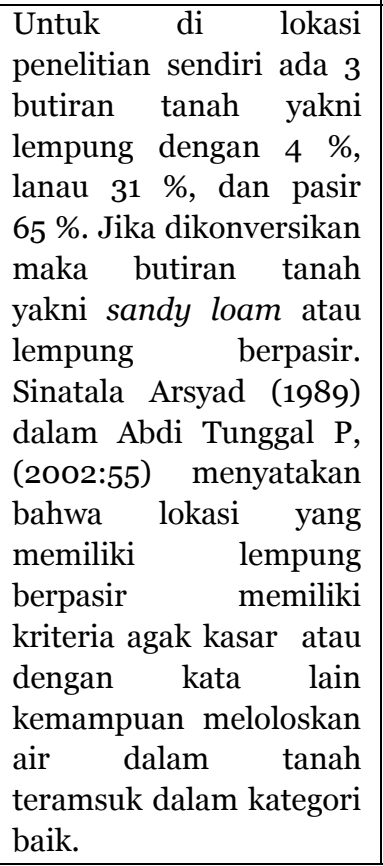 & 3 \\
\hline
\end{tabular}

Sumber : Fakta dan Data di Lapangan

\section{TEKNIK ANALISIS}

Peneltian yang berjudul "Analisis Klasifikasi Tingkat Kerentanan Daerah Rawan Banjir Berbasis Sistem Informasi Geografis" pada dasarnya memiliki 3 (tiga) variabel penelitian yakni Kemiringan Lereng, Penggunaan Lahan, dan Infiltrasi Tanah. Setelah 
menentukan variabel penelitian, kemudian dilakukan analisis yang terkait penentuan Klasifikasi Tingkat Kerentanan Daerah Rawan Banjir. Dalam penelitian kali ini memiliki 2 teknik analisis yakni Analisis Hierarcy Process Pairiwise Comparison dan Analisis Overlay Intersection. Maka dari itu akan dijabarkan teknik analisis tersebut dibawah ini :

\section{a. AHP Pairwise Comparison}

> Buatkan matriks pairwise comparison sesuai dengan tingkat kepentingan yang telah dijelaskan sebelumnya :

Tabel 5. MATRIX PAIRWISSE COMPARISON

\begin{tabular}{|l||c|c|c|}
\hline $\begin{array}{c}\text { VAR. } \\
\text { PENELITIAN }\end{array}$ & SLOPE & LANDUSE & INFILTRASI \\
\hline \hline SLOPE & 1 & 2 & 3 \\
\hline LANDUSE & $1 / 2$ & 1 & $3 / 2$ \\
\hline INFILTRASI & $1 / 3$ & $2 / 3$ & 1 \\
\hline
\end{tabular}

Sumber : AHP Pairwise Comparison 2017

> Kemudian ubah angka di dalam matriks tersebut ke dalam desimal agar mudah memecahkannya :

Tabel 6. MATRIX PAIRWISSE COMPARISON DALAM BENTUK DESIMAL

\begin{tabular}{|l||c|c|c|}
\hline $\begin{array}{c}\text { VAR. } \\
\text { PENELITIAN }\end{array}$ & SLOPE & LANDUSE & INFILTRASI \\
\hline \hline SLOPE & 1 & 2 & 3 \\
\hline LANDUSE & 0,50 & 1 & 1,50 \\
\hline INFILTRASI & 0,33 & 0,67 & 1 \\
\hline TOTAL & 1,83 & 3,67 & 5,50 \\
\hline
\end{tabular}

Sumber : AHP Pairwise Comparison 2017

Bagi elemen dengan total penjumlahan per kolom variabel penelitian :

Tabel 7

Matrix Pairwisse Comparison

\begin{tabular}{|l||c|c|c|}
\hline VAR. PENELITIAN & SLOPE & LANDUSE & INFILTRASI \\
\hline \hline SLOPE & 0,546 & 0,545 & 0,545 \\
\hline LANDUSE & 0,273 & 0,272 & 0,273 \\
\hline INFILTRASI & 0,180 & 0,183 & 0,182 \\
\hline
\end{tabular}

Sumber : AHP Pairwise Comparison 2017

Setelah itu, tentukan eigen vektornya dengan cara jumlahkan seluruh total baris per variabel penelitian kemudian bagi dengan jumlah variabel penelitian tersebut :

\section{Tabel 8}

Matrix Pairwisse Comparison

\begin{tabular}{|l||c|c|c|c|c|}
\hline $\begin{array}{c}\text { VARIABEL } \\
\text { PENELITIAN }\end{array}$ & SLOPE & LANDUSE & INFILTRASI & $\begin{array}{c}\text { JUMLAH } \\
\text { BARIS }\end{array}$ & $\begin{array}{c}\text { EIGEN } \\
\text { VEKTOR }\end{array}$ \\
\hline \hline SLOPE & 0,546 & 0,545 & 0,545 & 1,637 & 0,545 \\
\hline LANDUSE & 0,273 & 0,272 & 0,273 & 0,818 & 0,272 \\
\hline INFILTRASI & 0,180 & 0,183 & 0,182 & 0,545 & 0,181 \\
\hline
\end{tabular}

Sumber : AHP Pairwise Comparison 2017

Setelah mendapatkan jumlah baris per variabel penelitian dan eigen vektor, kemudian kali-kan jumlah baris denga eigen vektor per variabel penelitian. Hasil dari perkalian tersebut adalah bobot setiap variabel penelitian.

Tabel 9.MATRIX PAIRWISSE COMPARISON

\begin{tabular}{|l||c|c|c|c|}
\hline & $\begin{array}{c}\text { JUMLAH } \\
\text { BARIS }\end{array}$ & $\begin{array}{c}\text { EIGEN } \\
\text { VEKTOR }\end{array}$ & HASIL & BOBOT \\
\hline \hline SLOPE & 1,637 & 0,545 & 0,893 & 0,89 \\
\hline LANDUSE & 0,818 & 0,272 & 0,223 & 0,22 \\
\hline INFILTRASI & 0,545 & 0,181 & 0,099 & 0,10 \\
\hline
\end{tabular}

Sumber : AHP Pairwise Comparison 2017

Berdasarkan pembobotan Pairwise Comparison maka rumus untuk kriteria Peta rentan banjir di Kecamatan Sekarbela adalah (o,89*Slope) + $\left(0,22^{*}\right.$ Landuse $)+\left(0,10^{*}\right.$ Infiltrasi $)$.

> Setelah didapatkan bobot tiap variabelnya, kemudian hitung indeks konsistensnya. Fungsi Indeks Konsistensi (IC) adalah untuk meneatapkan layak atau tidaknya skor tiap variabel tersebut untuk dilanjutkan. Jika (IC) $<10 \%$ atau $<0,10$ berarti penelitian dapat dilanjutkan sesuai tahap penelitiannya. Tapi jika $>10 \%$ atau $>0,10$ berarti penelitian untuk variabel penelitiannya dianggap tidak sesuai dengan aturan pengerjaannya.

> Menghitung Rasio Konsistensi, yaitu dengan menentukan nilai Eigen Maksimum ( $\lambda$ maks) yang diperoleh dengan menjumlahkan hasil perkalan jumlah kolom tabel Pairwise Comparison ke bentuk desimal dengan Eigen Vektornya. Jika diketahui

$\lambda$ maks

: Jumlah dari Kolom Pairwise Comparison dan Eigen Vektor

$\mathrm{N} \quad$ : Jumlah Variabel

Tabel 1o.PENGHITUNGAN $\lambda$ MAKSIMAL

\begin{tabular}{|l||c|c|c|}
\hline & JUMLAH & EIGEN & Nilai \\
BARIS & VEKTOR & Maksimal \\
\hline \hline SLOPE & 1,83 & 0,545 & 0,99735 \\
\hline LANDUSE & 3,67 & 0,272 & 0,99824 \\
\hline INFILTRASI & 5,56 & 0,181 & 1,01192 \\
\hline \multicolumn{3}{|c|}{$\lambda$ Maksimal } & 3,00751 \\
\hline
\end{tabular}

Menghitung (IC)

$$
\begin{aligned}
& \text { IC }=\frac{\lambda \text { maks }-n}{n-1} \\
& =\frac{3,00751-3}{3-1} \\
& \text { IC }=\frac{0,00751}{2} \\
& =0,00674
\end{aligned}
$$

IC

Jika mengacu pada aturan bahwa IC harus dibawah $10 \%$ atau 0,10 maka IC yang telah didapatkan yakni o,00674. Melalui penghitungan ini menunjukkan bahwa 
penelitian ini dapat dilanjutkan karena IC nya kurang dari $10 \%$ atau 0,10 .

b. Penetuan Kelas Interval

Untuk menentukan tingkat klasifikasi banjir, terlebih dahulu menentukan kelas interval. Pengelompokan tingkat kerentanan banjir dalam penelitian kali ini memiliki 3 (tiga) tingkat yakni Sangat Rentan, Rentan dan Tidak Rentan. Pemilihan 3 (tiga) tingkat kerentanan ini juga memiliki beberapa pertimbangan yakni agar tidak jadi ketimpangan yang sangat jauh ketika menentukan kelas intrevalnya, menyamakan tingkat kerentanan dan variabel menjadi factor utama. Selain ditentukan jumlah tingkat kerentanannya, penghitungan kelas interval juga menjadi hal yang harus dilakukan agar memudahkan dalam melakukan penjumlahan. Maka dari itu untuk menentukan kelas interval terebut memilki rumus sebagai berikut :

Jumlah Kelas yang diinginkan $=1+3,22$ Log5 (Jumlah Sub-Wilayah)

$$
\begin{gathered}
=1+3,22(0,70) \\
=3,3=>4
\end{gathered}
$$

Jadi jumlah kelas yang diinginkan adalah 4 . Setelah itu, hitung jumlah Kelas Interval yang akan diterapkan pada penelitian kali ini. Maka dari itu rumus yang digunakan adalah :

$$
\begin{aligned}
& K I=\frac{\text { Bobot Tertinggi }- \text { Bobot Terendah }}{\text { Jumlah Kelas yang Diinginkan }} \\
& K I=\frac{\text { Bobot Tertinggi }- \text { Bobot Terendah }}{\text { Jumlah Kelas yang Diinginkan }} \\
& \mathrm{KI}=\frac{(0,89 \times 25)+(0,22 \times 15)+(0,10 \times 10)-(0,89 \times 5)+(0,22 \times 3)+(0,10 \times 2)}{4} \\
& \mathrm{KI}=\frac{26,55-5,31}{4} \\
& \mathrm{KI}=\frac{21,24}{4} \\
& \mathrm{KI}=5,31
\end{aligned}
$$

Jadi dari hasil rumus yang telah digunakan Kelas Interval (KI) untuk penelitian kali ini adalah 5,31 . Dengan bobot tertinggi 26,55 serta bobot terendah 5,31 .

Tabel 11.PEMBAGIAN KELAS INTERVAL

\begin{tabular}{|c|c|c|}
\hline NO & KELAS INTERVAL & KRITERIA \\
\hline \hline 1 & $5,31-10,62$ & TIdak Rentan \\
\hline 2 & $10,63-15,93$ & Cukup Rentan \\
\hline 3 & $15,94-21,24$ & Rentan \\
\hline 4 & $21,25-26,55$ & Sangat Rentan \\
\hline
\end{tabular}

Sumber : AHP Pairwise Comparison 2017

\section{PEMBAHASAN}

\section{GAMBARAN UMUM}

Kecamatan Sekarbela adalah salah satu Kecamatan yang berada di Kota Mataram. Dengan letak geografis 8028'30" LS - 8021'o" LS dan 11601'30"
BT - 11609'0"BT serta memiliki 5 Kelurahan yakni Kelurahan Kekalik Jaya, Karang Pule, Tanjung Karang, Tanjung Karang Permai dan Jempong. Dengan memiliki 5 Kelurahan, Kecamatan yang berbatasan langsung dengan Selat Lombok ini memiliki luas wilayah $10,31 \mathrm{~km}^{2}$ serta keseluruhan wilayahnya adalah dataran rendah. Maka dari itu batas wilayah Kecamatan Sekarbela adalah :
Sebelah Barat
: Selat Lombok
Sebelah Timur
: Kecamatan Mataram
Sebelah Utara
: Kecamatan Ampenan
Sebelah Selatan

Tabel 12.LUAS WILAYAH KECAMATAN SEKARBELA TAHUN 2015

\begin{tabular}{|c|l|c|c|}
\hline \hline NO & KELURAHAN & $\begin{array}{c}\text { LUAS } \\
\text { WILAYAH } \\
(\text { Ha) }\end{array}$ & $\begin{array}{c}\text { PERS. } \\
(\%)\end{array}$ \\
\hline \hline 1 & Kekalik Jaya & 144.53 & 12.89 \\
2 & Tg. Karang & 58.58 & 5.22 \\
& Permai Karang & 155.03 & 13.83 \\
3 & Tanjung Kule & 249.41 & 22.24 \\
4 & Karang Pule & 513.69 & 45.81 \\
\hline \multicolumn{2}{|l|}{ Jempong Baru } & $\mathbf{1 . 1 2 1 . 2 5}$ & $\mathbf{1 0 0}$ \\
\hline
\end{tabular}

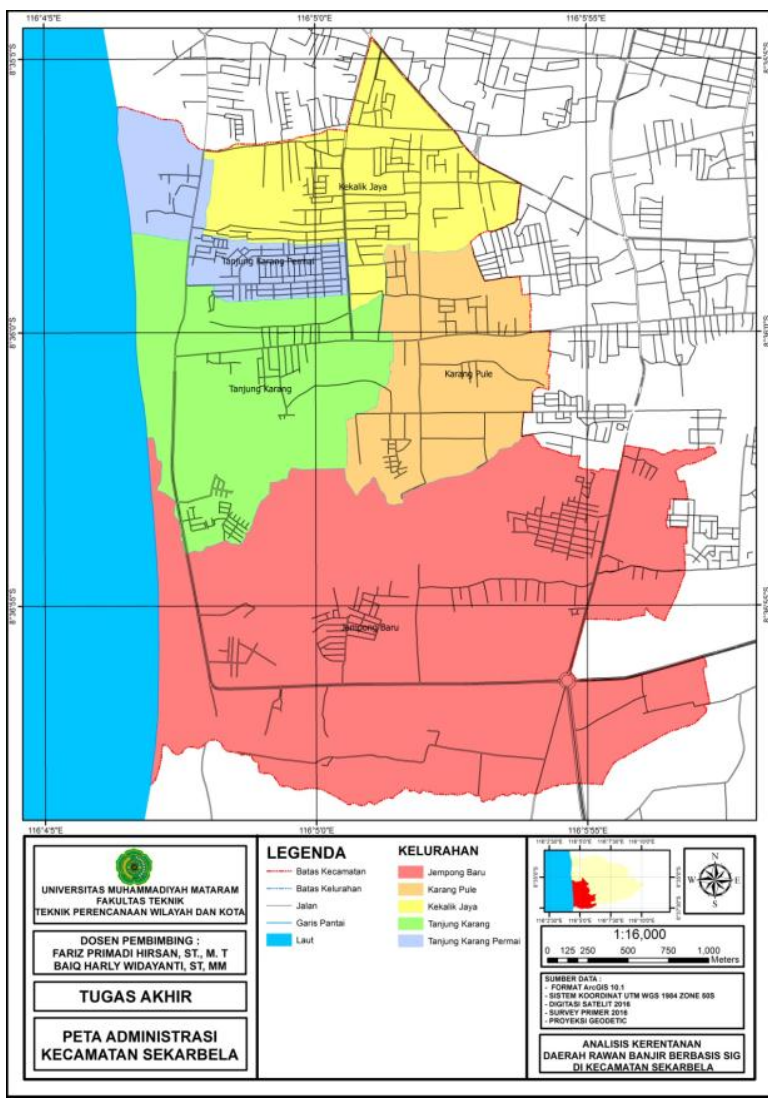

Sumber : Pemetaan Digital Berbasis SIG

Gambar 1. Peta Batas Administrasi Kecamtan Sekarbela

\section{ANALISIS PAIRWISE COMPARISON}

Analisa AHP dengan metode Pairwise Comparison ditujukan untuk menentukan tingkat kepentingan (skala prioritas) dari parameter Kemiringan Lereng, Penggunaan Lahan dan Infiltrasi 
Tanah yang dipakai sebagai parameter pada analisa daerah rawan banjir ini. Kriteria yang digunakan atas tiga parameter akan dijelaskan menurut tingkat kepentingannya sebagai berikut:

Tabel 13.MATRIX PAIRWISSE COMPARISON

\begin{tabular}{|l|r|r|r|r|}
\hline & $\begin{array}{c}\text { JUMLAH } \\
\text { BARIS }\end{array}$ & $\begin{array}{c}\text { EIGEN } \\
\text { VEKTOR }\end{array}$ & \multicolumn{1}{l|}{ HASIL } & BOBOT \\
\hline \hline SLOPE & 1,637 & 0,545 & 0,893 & 0,89 \\
\hline LANDUSE & 0,818 & 0,272 & 0,223 & 0,22 \\
\hline INFILTRASI & 0,545 & 0,181 & 0,099 & 0,10 \\
\hline
\end{tabular}

Sumber : AHP Pairwise Comparison 2017

Sehingga berdasarkan pembobotan Pairwise Comparison maka rumus untuk kriteria Peta rentan banjir di Kecamatan Sekarbela adalah (o,89*Slope) + $\left(0,22^{*}\right.$ Landuse $)+\left(0,10^{*}\right.$ Infiltrasi). Dari hasil analisa AHP Pairwise Comparison ditemukan bobot per variabel penelitian yakni (o,89*Slope) $\left(0,22^{*}\right.$ Landuse $)+\quad\left(0,10^{*}\right.$ Infiltrasi $)$. Setelah ditemukan bobot tersebut, selanjutnya bobot tersebut dihitung sesuai dengan variabel penelitiannya dengan mempertimbangkan zona yang akan dihitung.

\section{PEMBAGIAN ZONA}

Penentuan zona ini didasari oleh beberapa landasan yakni ;

1. Keanekaragaman sub-zona berdasarkan penggunaan lahan;

2. Pembatasan sub-zona berdasarkan batas wilayah Kelurahan dan jalan;

3. Memudahkan peneliti dalam menentukan zona; dan

4. Penetapan sub-zona berdasarkan pemanfaatan lahan yang tersedia.

Tabel 14.PEMBAGIAN ZONA KLASIFIKASI RENTAN BANJIR DI KELURAHAN TANJUNG KARANG

\begin{tabular}{|c|c|c|l|l|r|}
\hline $\begin{array}{c}\text { N } \\
\text { O }\end{array}$ & $\begin{array}{l}\text { SUB- } \\
\text { ZONA }\end{array}$ & $\begin{array}{c}\text { SLO } \\
\text { PE }\end{array}$ & AND USE & $\begin{array}{c}\text { SOIL } \\
\text { INFILTRATION }\end{array}$ & $\begin{array}{c}\text { LUA } \\
\text { S }\end{array}$ \\
\hline 1 & A1 & $\begin{array}{l}\text { Land } \\
\text { ai }\end{array}$ & $\begin{array}{l}\text { Permuki } \\
\text { man }\end{array}$ & $\begin{array}{l}\text { Lempung } \\
\text { Berpasir }\end{array}$ & $\begin{array}{r}0.15 \\
9\end{array}$ \\
\hline 2 & A2 & $\begin{array}{l}\text { Land } \\
\text { ai }\end{array}$ & $\begin{array}{l}\text { Permuki } \\
\text { man }\end{array}$ & $\begin{array}{l}\text { Lempung } \\
\text { Berpasir }\end{array}$ & $\begin{array}{r}0.18 \\
5\end{array}$ \\
\hline & A3 & $\begin{array}{l}\text { Land } \\
\text { ai }\end{array}$ & $\begin{array}{l}\text { Permuki } \\
\text { man }\end{array}$ & $\begin{array}{l}\text { Lempung } \\
\text { Berpasir }\end{array}$ & $\begin{array}{r}0.16 \\
1\end{array}$ \\
\hline 4 & A4 & $\begin{array}{l}\text { Land } \\
\text { ai }\end{array}$ & $\begin{array}{l}\text { Permuki } \\
\text { man }\end{array}$ & $\begin{array}{l}\text { Lempung } \\
\text { Berpasir }\end{array}$ & $\begin{array}{r}0.08 \\
8\end{array}$ \\
\hline & A5 & $\begin{array}{l}\text { Land } \\
\text { ai }\end{array}$ & $\begin{array}{l}\text { Permuki } \\
\text { man }\end{array}$ & $\begin{array}{l}\text { Lempung } \\
\text { Berpasir }\end{array}$ & $\begin{array}{r}0.09 \\
5\end{array}$ \\
\hline
\end{tabular}

Sumber : Survey Primer 2017 dan Digitasi ArcGIS 10.3

\section{PENETAPAN KLASIFIKASI TINGKAT} KERENTANAN BANJIR

Tabel 15. KLASIFIKASI TINGKAT KERENTANAN BANJIR DI KELURAHAN TANJUNG KARANG

\begin{tabular}{|c|c|c|c|c|c|c|c|c|c|c|c|c|c|c|c|}
\hline \multirow{3}{*}{ 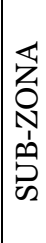 } & \multirow{2}{*}{\multicolumn{3}{|c|}{$\begin{array}{c}\text { KEM. } \\
\text { LERENG }\end{array}$}} & \multirow{2}{*}{\multicolumn{3}{|c|}{$\begin{array}{l}\text { PENG. } \\
\text { LAHAN }\end{array}$}} & \multirow{2}{*}{\multicolumn{3}{|c|}{$\begin{array}{c}\text { INF. } \\
\text { TANAH } \\
\text { IT }\end{array}$}} & \multirow{2}{*}{\multicolumn{3}{|c|}{$\begin{array}{l}\text { SKOR } \\
\text { INTER. }\end{array}$}} & \multirow{3}{*}{$\begin{array}{l}\text { TOTAL } \\
\text { INTER }\end{array}$} & \multirow{3}{*}{\multicolumn{2}{|c|}{ 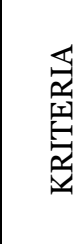 }} \\
\hline & & & & & & & & & & & & & & & \\
\hline & $\mathrm{H}$ & B & $\mathrm{S}$ & $\mathrm{H}$ & B & $\mathrm{S}$ & $\mathrm{H}$ & B & $\mathrm{S}$ & $\nabla$ & 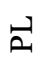 & 壬 & & & \\
\hline $\begin{array}{l}\mathrm{A} \\
1\end{array}$ & 4 & 5 & $\begin{array}{l}2 \\
0\end{array}$ & 4 & 3 & $\begin{array}{l}1 \\
2\end{array}$ & 2 & 2 & 4 & $\stackrel{\infty}{\sim}$ & $\begin{array}{l}\text { ல } \\
\text { ஸे }\end{array}$ & $\stackrel{+}{0}$ & 20.84 & 急 & E \\
\hline $\begin{array}{l}\mathrm{A} \\
2\end{array}$ & 4 & 5 & $\begin{array}{l}2 \\
0\end{array}$ & 4 & 3 & $\begin{array}{l}1 \\
2\end{array}$ & 2 & 2 & 4 & $\stackrel{\infty}{\sim}$ & $\begin{array}{l}\text { ல } \\
\text { ஸ் }\end{array}$ & $\stackrel{+}{\circ}$ & 20.84 & 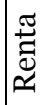 & I \\
\hline $\begin{array}{l}\mathrm{A} \\
3\end{array}$ & 4 & 5 & $\begin{array}{l}2 \\
0\end{array}$ & 4 & 3 & $\begin{array}{l}1 \\
2\end{array}$ & 2 & 2 & 4 & $\stackrel{\infty}{-}$ & $\begin{array}{l}\text { Ð } \\
\text { ஸे }\end{array}$ & $\stackrel{+}{\circ}$ & 20.84 & 急 & I \\
\hline $\begin{array}{l}\mathrm{A} \\
4\end{array}$ & 4 & 5 & $\begin{array}{l}2 \\
0\end{array}$ & 5 & 3 & 15 & 2 & 2 & 4 & $\stackrel{\infty}{\infty}$ & ๓ं & $\stackrel{+}{\circ}$ & 21.5 & $\pi$ & 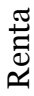 \\
\hline $\begin{array}{l}\text { A } \\
5\end{array}$ & 4 & 5 & $\begin{array}{l}2 \\
0\end{array}$ & 4 & 3 & $\begin{array}{l}1 \\
2\end{array}$ & 2 & 2 & 4 & $\stackrel{\infty}{\infty}$ & $\begin{array}{l}\text { Jे } \\
\text { ì }\end{array}$ & $\stackrel{+}{\circ}$ & 20.84 & 苞 & శ \\
\hline
\end{tabular}

Sumber : Overlay Intersection 2017

$$
\begin{aligned}
& \text { H : Harkat S : Skor } \\
& \text { B : Bobot }
\end{aligned}
$$

\section{ANALISIS OVERLAY INTERSECTION}

Pada proses overlay kali ini dibutuhkan beberapa data yakni dalam bentuk peta yaitu Peta Kemiringan, Peta Penggunaan Lahan, dan Peta Infiltrasi Tanah. Ketiga peta ini akan diolah dalam pemetaan digital yakni ArcGIS 10.3 yang akan diklasifikasikan menjadi 3 (tiga) tingkatan yakni Sangat Rentan, Rentan, dan Tidak Rentan. Pengambilan 3 (tiga) klasifikasi ini salah satunya didasari oleh variabel penelian yang berjumlah 3 (tiga) juga. Berikut langkah overlay peta menggunankan metode Intersection pada ArcGIS 10.3:

a. Tambahkan peta dari masing-masing parameter yakni Peta Kemiringan, Peta Penggunaan Lahan, dan Peta Infiltrasi Tanah yang sebelumnya telah diisi atribut sesuai dengan kebutuhan, serta tambahkan pula peta lokasi penelitian. 


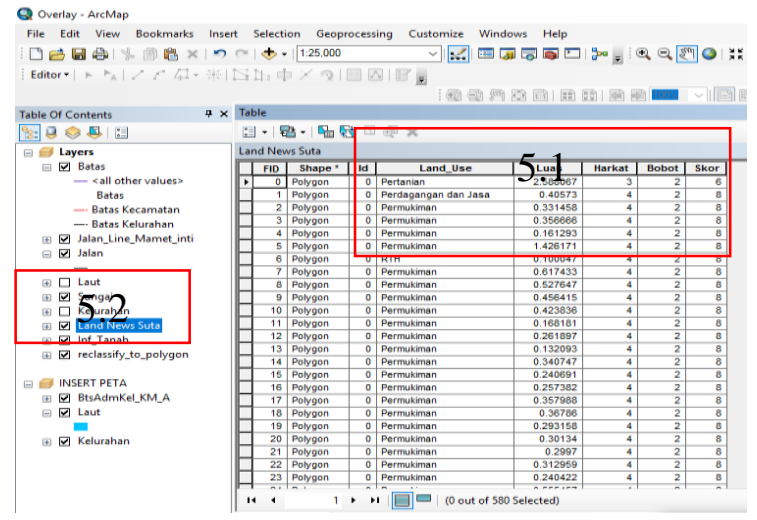

Gambar 2. Shape File Land Use Yang Telah Dilakukan Pengisian Data Atribut

b. Pada Arctoolbox pilih Analysis Tool, pilih Overlay, pilih Intersect dan masukkan masing-masing parameter sesuai dengan nilai pembobotannya dari yang memiliki nilai bobot terbesar sampai terkecil.

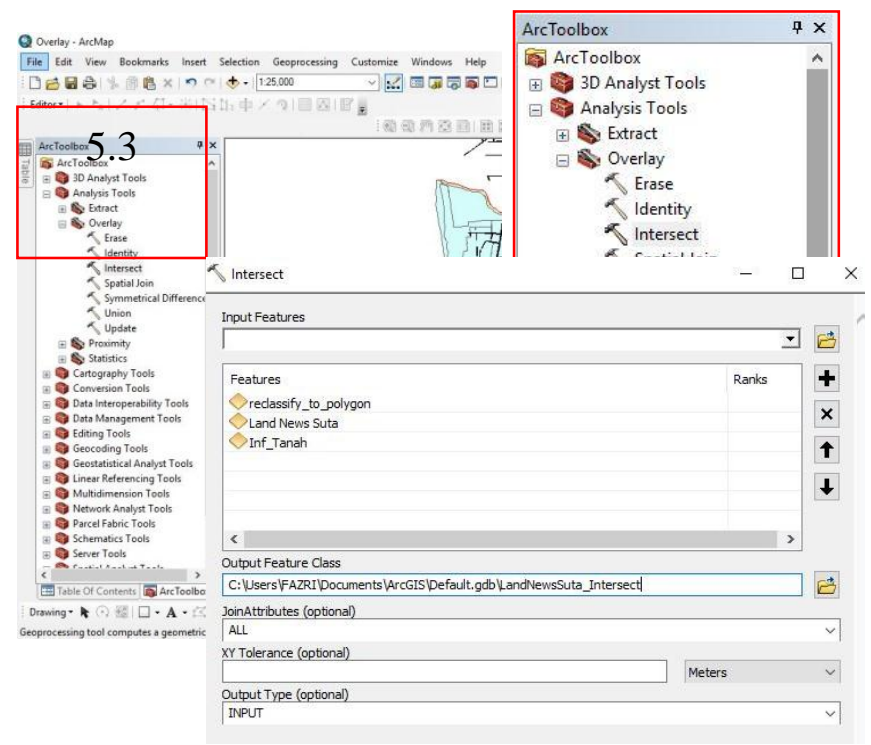

Gambar 3. Langkah Dalam Melakukan Intersect Dalam ArcGIS 10.3

\begin{tabular}{|l|r|r|r|r||}
\hline Pertanian & 2.588067 & 3 & 2 & 6 \\
\hline Perdagangan dan Jasa & 0.40573 & 4 & 2 & 8 \\
\hline Permukiman & 0.331458 & 4 & 2 & 8 \\
\hline Permukiman & 0.356666 & 4 & 2 & 8 \\
\hline Permukiman & 0.161293 & 4 & 2 & 8 \\
\hline Permukiman & 1.426171 & 4 & 2 & 8 \\
\hline RTH & 0.100047 & 4 & 2 & 8 \\
\hline Permukiman & 0.617433 & 4 & 2 & 8 \\
\hline
\end{tabular}

Gambar 4.Masukkan Seluruh Variabel Penelitian Dalam Tabel Intersect

c. Setelah melakukan Intersect, akan tampil seperti pada gambar 5.5. Setelah itu export hasil intersect tersebut ke Ms. Excel dan masukkan rumus jumlah total nilai rentan banjir dari hasil Matriks Pairwise Comparison (0,89*Slope)+ $\left(0,22^{*}\right.$ Landuse $)+\left(0,10^{*}\right.$ Infiltrasi $)$. d. Setelah itu dikonversi dalam bentuk peta tematik

e. Hasil neta tersebut akan terlihat nada gambar 5

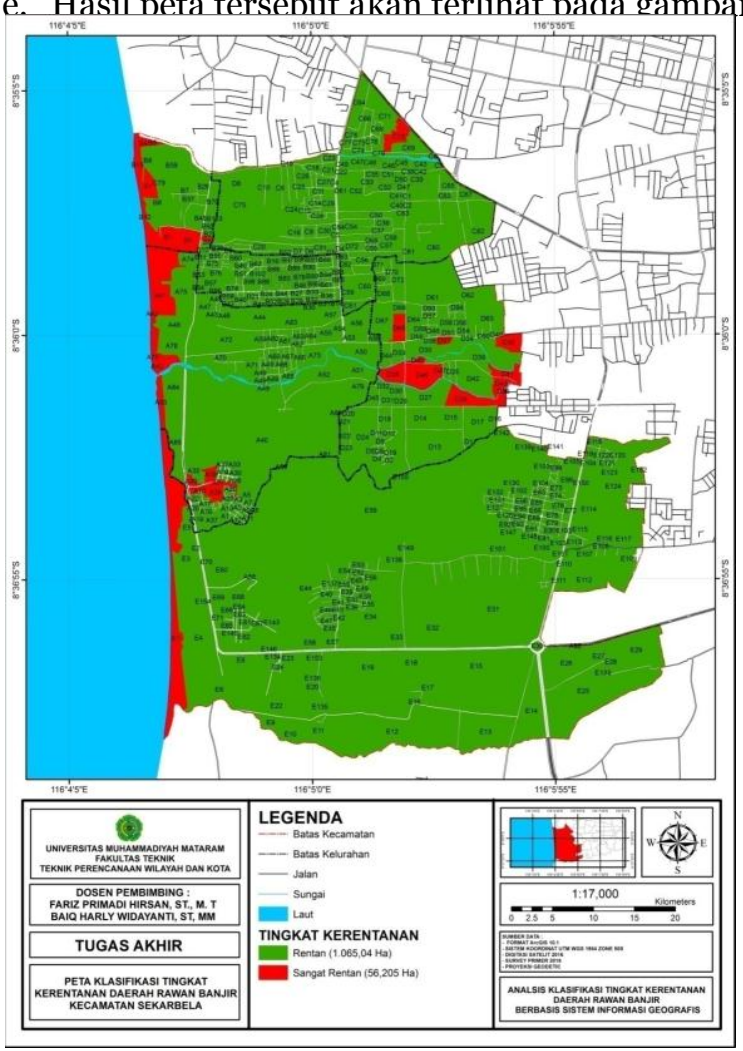

Gambar 5. Peta Klasifikasi Tingkat Kerentanan Daerah Rawan Banjir Kecamatan Sekarbela

\section{PEMETAAN ZONA KERENTANAN BANJIR}

Data-data yang digunakan sebagai parameter dalam penentuan tingkat kerentanan banjir pada penelitian ini antara lain, kemiringan lereng, Penggunaan Lahan dan Infiltrasi Tanah. Masing-masing parameter dinilai dengan cara pengharkatan sesuai dengan besarnya pengaruh terhadap tingkat kerentanan banjir di daerah penelitian. Parameter-parameter yang mempunyai tipe pengaruh yang besar terhadap terjadinya banjir diberi nilai/harkat yang besar pula begitu juga sebaliknya parameter dengan tipe pengaruh yang kecil terhadap terjadinya banjir akan diberi nilai/harkat yang kecil. Hasil analisis overlay tersebut kemudian diklasifikasi dan hasilnya adalah peta yang berisi kelas/tingkat kerentanan banjir di Kecamatan Sekarbela dengan memiliki 2 (dua) yakni Kelas Rentan dan Sangat Rentan.

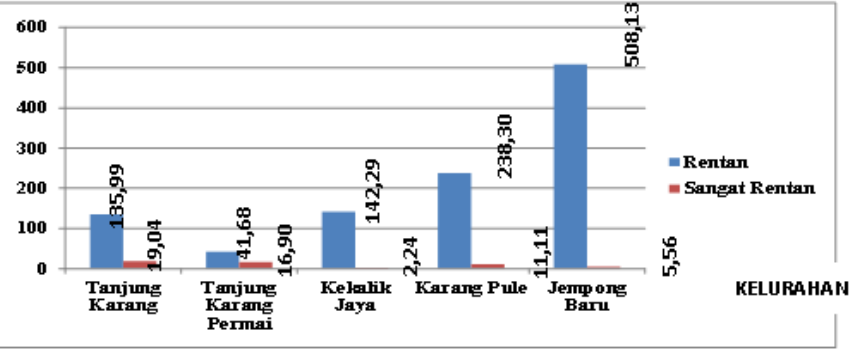

Gambar 6. Diagram Luas Wilayah Tingkat Kerentanan Daerah Rawan Banjir dirinci Per Kelurahan di Kecamatan Sekarbela 
Sumber : Pemetaan Digital ArcGIS 10.3
Kelurahan : A. Tanjung Karang
B. Tanjung Karang Permai
D. Karang Pule
E. Jempong Baru
C. Kekalik Jaya

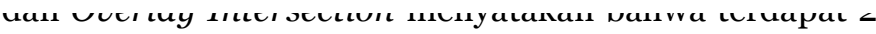

(dua) klasifikasi tingkat kerentanan yakni Rentan dan Sangat Rentan. Penentuan tingkat klasifikasi tersebut didapatkan dari hasil skor dimana skor 15,94 - 21,24 termasuk dalam kriteria Rentan dan 21,25 - 26,55 termasuk dalam kriteria Sangat Rentan. Untuk persentase wilayahnya, seluruh wilayhanya masuk dalam tingkat kerentanan banjir dengan persentase 95,11 \% wilayah yang termasuk dalam klasifikasi rentan dan 4,89 \% wilayah yang termasuk klasifikasi Sangat Rentan. Untuk lebih jelasnya akan dilakukan pejabaran setiap tingkat kerentanan.

\section{DAFTAR RUJUKAN}

\section{BUKU}

[1] BPS Kota Mataram. 2011-206. NTB Dalam Angka. Badan Pusat Statistik Nusa Tenggar Barat Mataram

\section{TULISAN ILMIAH}

[2] Ikmal, Andi Mahardy 2014. Analisis dan Pemetaan Daerah Rawan Banjir di Kota Makassar Berbasis Spatial, Kota Makassar

[3] Isunugroho., Joko, Agus Pratomo. 2008. Analisis Kerentanan Banjir di Daerah Aliran Sungai Sengkang Kabupaten Pekalongan Provinsi Jawa Tengah Dengan Bantuan Sistem Informasi Geogrfis. Kabupaten Pekalongan, Provinsi Jawa Tengah

[4] Latiful, M. Aziz. 2012. Pemetaan Tingkat Kerentanan dan Tingkat Bahaya Banjir Daerah Aliran Sungai (DAS) Bengawan Solo Bagian Tengah di Kabupaten Bojonegoro. Kabupaten Bojonegoro

[5] Nurhadi., Sumunar, Dyah Respati Suryo., Khotimah, Nurul. 2013. Analisis Kerentanan Banjir di Daerah Aliran Sungai (DAS) Code Kota Yogyakarta. Kota Yogyakarta

[6] Wibowo, Mardi. 2005. Analisis Pengaruh Perubahan Penggunaan Lahan Terhadap Debit Sungai di Gandok, Bandung 